\title{
Gesto: aliado ou vilão nos casos de atraso no desenvolvimento da linguagem?
}

\author{
Amanda L. Nogueira*; Carolina B. Bizutti*; Kelly C. B. da Silva.
}

\section{Resumo}

A clínica fonoaudiológica é lugar privilegiado no que concerne à análise e à discussão dos aspectos que compõem a linguagem e a função deles no processo aquisicional. Dessa forma, deve-se compreender que a linguagem é um conjunto multimodal (CAVALCANTE, 2012). Assim, a linguagem deve ser investigada em sua totalidade, uma vez que a gesticulação é parte essencial e intrínseca da aquisição da linguagem e surge antes da fala (CAVALCANTE; BRANDÃO, 2012). Logo, o presente trabalho tem o objetivo de analisar a presença de tais gestos durante o desenvolvimento do bebê. Para tal foi realizado um estudo qualitativo de caráter descritivo, recorte de uma pesquisa maior, intitulada "Sinais de risco e sofrimento psíquico na primeira infância: identificação e estratégicas de intervenção". Percebe-se que os gestos estão presentes antes mesmo que a fala se instale o que permite a avaliação do desenvolvimento da linguagem e de possíveis riscos ao desenvolvimento infantil, precocemente. Além disso, nota-se que ao longo do desenvolvimento os gestos se tornam mais elaborados, já que outros aspectos como a fala e a compreensão do outro como ser intencional vão se somando.

Palavras-chave: Linguagem, Gestualidade, Desenvolvimento

\section{Introdução}

A clínica fonoaudiológica é lugar privilegiado no que concerne à análise e à discussão dos aspectos que compõem a linguagem e a função deles no processo aquisicional. Sendo o fonoaudiólogo um dos profissionais que se depara com os casos nos quais o desenvolvimento da linguagem apresenta distúrbios. Porém, segundo Flores e Smeha (2013), geralmente, essa procura só ocorre após os 2 anos de idade. Fato que impossibilita uma intervenção precoce, e, consequentemente, melhores resultados terapêuticos, visto que o período de maior atividade da neuroplasticidade é dentro dos dois primeiros anos de vida do bebê. Assim, a linguagem deve ser investigada em sua totalidade, uma vez que a gesticulação é parte essencial e intrínseca da aquisição da linguagem e surge antes da fala (CAVALCANTE; BRANDÃO, 2012). Ressalta-se que há um contínuo de movimentos que compõem o que se chama de gestos, o "contínuo de Kendon" que é formado por gesticulação, pantomima e emblemas (CAVALCANTE; BRANDÃO, 2012). Dessa forma, essa pesquisa tem por objetivo avaliar a presença e a qualidade de tais gestos, a partir da observação da interação bebê-cuidador.

\section{Resultados e Discussão}

Os resultados encontrados são parciais e fazem parte de uma pesquisa. Foi realizada uma gravação da interação de quatro díades bebê-cuidador (bebês com $6,8,10$, e 17 meses). Foi observado que todos os bebês apresentaram a gesticulação (movimentos corporais acompanhados de fala ou balbucio), sendo que o bebê mais velho também produziu palavras. Em relação à pantomima (gestos sequenciais que têm caráter de narrativa), apareceu em dois, sendo que os cuidadores forneceram o padrão gestual. Já o emblema (gestos convencionais de uma determinada cultura) apareceu em todas as crianças, sendo nos bebês mais velhos o gesto emblemático foi o apontar, enquanto nos dois bebês mais novos o movimento apresentado foi o de esticar os braços em direção ao objeto desejado.

\section{Conclusões}

Ressalta-se a importância de um olhar integral à linguagem do bebê, uma vez que alterações nesse processo podem gerar dificuldades na constituição do sujeito e repercutir na socialização e aprendizagem da criança em período ulterior (RECHIA, 2016). Dessa forma, visto que a imaturidade biológica do bebê o coloca em uma posição de ser cuidado por outros (DE LEMOS, 1997). Assim, destaca-se que há a necessidade de orientar os cuidadores e profissionais que atuam com a primeira infância, a respeito desse aspecto do desenvolvimento para que a atenção a linguagem ocorra de forma global desde os primeiros meses de vida da criança, de forma a permitir a intervenção precoce em casos de distúrbios psíquicos e proporcionar meios para um melhor prognóstico.

\section{Agradecimentos}

Fundação de Amparo à Pesquisa do Estado de São Paulo (FAPESP).

Usar esse espaço para referências, seguindo o estilo indicado - Padrão ACS ou CAVALCANTE, Marianne Carvalho Bezerra. Hologestos: produções linguísticas numa perspectiva multimodal. Revista de Letras (Fortaleza). v. 31(1/2), p. 7-14, 2012.

Marianne Carvalho Bezerra; BRANDÃO, Lavínia Wanderley Pinto. Gesticulação e

Fluência: contribuições para a aquisição da linguagem. Cadernos de Estudos Linguísticos (UNICAMP). v. 1, p. 55-66, jan/jun 2012.

FLORES, Mariana Rodrigues; SMEHA, Luciane Najar. Bebês com risco de autismo: o nãoolhar do médico. Ágora. Rio de Janeiro, v. 16, n. spe, p. 141-157, abr. 2013

LEMOS, C. T. G. de. Processos Metafóricos e Metonímicos: seu Estatuto Descritivo Explicativo na Aquisição da Língua Materna. Trabalho apresentado no The Trend Lectures and Workshop on Metaphorand Analogy, Trento, Itália, 1997.

RECHIA, Inaê Costa. Maturação da via auditiva e a aquisição da linguagem em crianças nascidas pré termo tardio e a termo com e sem risco psíquico. (Tese de doutorado) Universidade Federal de Santa Maria. Rio grande do Sul. 2016. 